\title{
E-LEARNING DI ERA PANDEMI COVID-19: BAGAIMANA AKSIOLOGI HASIL BELAJAR PENDIDIKAN JASMANI?
}

\section{E-LEARNING IN THE COVID-19 PANDEMIC ERA: HOW DOES THE AXOLOGY RESULT OF LEARNING PHYSICAL EDUCATION?}

\author{
Aulia Gusdernawati ${ }^{1 *}$, Povian Yona Mahatmasari², Wawan S Suherman ${ }^{3}$, Ahmad \\ Nasrulloh $^{4}$, Kamilia Lituhayu ${ }^{5}$, Aji Khotibul Umam ${ }^{6}$
}

\author{
Program Pascasarjana, Ilmu Keolahragaan, Universitas Negeri Yogyakarta
}

*Corresponding Author: Aulia Gusdernawati, auliagusdernawati.2020@student.uny.ac.id

Received: 2021-01-30; Revised: 2021-02-19; Accepted: 2021-03-01

\begin{abstract}
Abstrak
Pelaksanaan pendidikan di sekolah mengandung nilai-nilai meliputi tanggung jawab,kedisiplinan, kemandirian, kejujuran, kreativitas serta sosial. Pandemi Covid-19 yang terjadi saat ini menjadikan penghalang untuk melakukan pembelajaran di sekolah sehingga dialihkan menjadi e-learning. Tujuan penelitian ini adalah untuk mengetahui bagaimana aksiologi hasil belajar pendidikan jasmani melalui e-learning di era pandemi Covid-19. Penelitian ini merupakan penelitian korelasional yang menggunakan populasi SMP se-Yogyakarta. Subjek penelitian berjumlah 120 orang. Instrumen pengambilan data menggunakan kuesioner dengan jenis skala likert dengan nilai validitas dan reliabilitas dari kuesioner dengan nilai 0,887. Hasil penelitian ini menjelaskan bahwa tidak terdapat hubungan nilai aksiologi hasil belajar pendidikan jasmani melalui $e$-learning di era pandemi Covid-19 dengan nilai signifikan 0,264 . Nilai aksiologi yang didapatkan pada hasil belajar pendidikan jasmani tersebut masuk dalam kategori rendah. Hasil belajar e-learning ini diharapkan agar siswa tetap dapat meningkatkan nilai aksiologi. Peningkatan tersebut dapat dilakukan dengan pembiasaan dalam lingkungan siswa, baik lingkungan keluarga, sekolah maupun sosial
\end{abstract}

Kata Kunci: Aksiologi, Hasil Belajar, E-Learning

\begin{abstract}
Education in school contains values of responsibility, discipline, independence, honesty, creativity, and social. Pandemic COVID-19 changes and drives the implementation of learning to become online. This study aims to determine how the axiology in physical education learning through e-learning in the era of the Covid-19 pandemic. This paper is a correlational study which population is Junior High School in Yogyakarta and 120 students. The data collection instrument is a questionnaire using Likert scale with 0,887 of validity and reliability. The result of this study proved that there is no axiological value relationship in physical education learning through e-learning in the COVID-19 pandemic era with 0.264 significant value. The axiological value obtained is in the low category of physical education learning through e-learning in this pandemic era. It is hoped that students can improve the value of axiology in this online learning session. This increase can be done by habituation in the environment of student"s families, school, and social.
\end{abstract}

Keywords: Axiology, Learning Outcomes, E-Learning

How To Cite: Gusdernawati. A., Mahatmasari, P.Y., Suherman, W.S., Nasrulloh. A., Lituhayu. K., Umam, A.K. (2021). E-learning di era pandemi covid-19: bagaimana aksiologi hasil belajar pendidikan jasmani?. Journal of Sport Education (JOPE), 3 (2), 63-74. doi: http://dx.doi.org/10.31258/jope.3.2.63-74

Journal of Sport Education (JOPE) is an open access article under the CC-BY-SA 4.0 License 


\section{PENDAHULUAN}

Pendidikan merupakan salah satu usaha yang dapat dilakukan di sekolah kepada siswa. Hal ini dimaksudkan agar siswa memiliki kemampuan serta dapat mengembangkan potensi yang dimiliki (Siregar, 2017) Pada hakikatnya pendidikan memiliki pengertian yaitu, salah satu usaha yang dilakukan guna mengembangkan, membimbing, dan memberikan arahan untuk meningkatkan potensi serta kepribadian siswa agar memiliki kepribadian luhur dan berakhlak mulia (Chasanah, 2017). Pendidikan yang dilakukan siswa di sekolah memiliki proses pembelajaran di dalamnya. Proses pembelajaran akan berlangsung dengan adanya interaksi antara seorang guru dan lingkungannya, sehingga proses pembelajaran tersebut dapat dilaksanakan di mana saja (Raibowo \& Nopiyanto, 2020). Oleh karenanya pendidikan harus menanamkan keseluruhan nilai dan norma moral kepada peserta didik dan dapat diterapkan dalam kehidupan sehari-hari (Putri, 2013).

Membangun norma moral dan budipekerti sebagai pendidikan karakter sangat dibutuhkan dalam pendidikan, baik itu pendidikan formal maupun pendidikan nonformal (Wahono, 2018). Berdasarkan penjelasan tersebut, dapat disimpulkan bahwa pendidikan tidak hanya sebuah proses untuk mengasah pengetahuan dan keterampilan melainkan juga pembentukan pribadi yang di dalamnya terdapat aspek jasmani, akal, dan hati. Berbicara mengenai pendidikan serta pembelajaran, hakikatnya pendidikan merupakan bagian dari filsafat ilmu. Terdapat beberapa bagian yang tergabung dalam filsafat ilmu. Salah satu yang paling sering dikaitkan pada pendidikan adalah aksiologi. Aksiologi yang dimaksudkan meliputi beberapa nilai yang terkandung di dalamnya yaitu, nilai hakikat, asal, dan keabadian (Tomar, 2014).

Aksiologi filsafat ilmu berhubungan dengan nilai yang berkaitan dengan kegunaan dari pengetahuan yang didapatkan atau diperoleh (Suriasumantri, 2015).Nilai yang dimaksudkan dalam aksiologi merupakan aspek yang sangat penting dalam kehidupan dan berkaitan dengan karakter. Karakter yang dimiliki oleh seseorang memiliki beberapa komponen yaitu bagaimana sikap yang ditetapkan terhadap Tuhan-Nya, antar sesama, diri sendiri dan lingkungan sekitar (Winata et al., 2020).

Melanjutkan penjelasan mengenai nilai, aksiologi ialah cabang filsafat yang menganalisis dan memfokuskan segala sesuatu yang berkaitan dengan nilai. Selain itu, juga memiliki fokus kajian dalam menganalisis hakikat nilai atau segala hal yang bersangkutan dengan nilai (Sirojudin \& Ashoumi, 2020). Jika ditelaah lebih jauh mengenai nilai yang dibahas berdasarkan filsafat ilmu, nilai merupakan hubungan antara manusia sebagai subjek dengan kemampuan akalnya untuk menangkap pengetahuan tentang kualitas objek-objek yang ada di sekitarnya (Soeprapto, 2013). Berkenaan dengan pembahasan aksiologi dan nilai yang ada dalam sistem pendidikan merupakan hal penting yang harus diperhatikan. Hal ini dapat dilihat kaitannya dengan pembenaran aksiologi prioritas dan navigator nilai kegiatan pendidikan. Aksiologi juga diungkapkan sebagai salah satu moral pendidikan. Lebih lanjut, di dalam aksiologi pendidikan akan menggambarkan mengenai konsep pendidikan, tujuan, metode, prinsip, dan cita-cita (Aleksandrovich, 2013). Berbicara tentang aksiologi yang menjadi moral pendidikan, saat ini terdapat permasalahan serius pada dunia pendidikan serta pembelajaran. Permasalahan yang terjadi tidak terlepas dari dampak akibat pandemi Covid19. Pandemi yang terjadi memberikan perubahan pembelajaran yang mulanya tatap muka langsung kini menjadi online. Sistem pendidikan online sering disebut juga sebagai dalam jaringan atau e-learning (Haerudin et al., 2020).

Jauh sebelum masa pandemi Covid-19 kita sudah mengenal e-learning yang merupakan sebuah inovasi untuk memudahkan siswa menerima materi pembelajaran yang dapat diakses dengan internet, namun e-learning ini mempunyai keterbatasan akses internet dan perangkat yang digunakan menjadi penyebab tidak maksimal dalam penggunaan e-learning (Dwi et al., 
Aulia Gusdernawati ${ }^{*}$, Povian Yona Mahatmasari², Wawan S Suherman ${ }^{3}$, Ahmad Nasrulloh4, Kamilia Lituhayu ${ }^{5}$, Aji Khotibul Umam ${ }^{6}$

2020). Dimasa pandemi pembelajaran e-learning merupakan upaya yang dilakukan pemerintah untuk tetap menjalankan proses pendidikan pada semua jenjang pendidikan formal sebagai adaptasi adanya pandemi Covid-19 (Kemendikud, 2020). Keadaan ini mengharuskan semua kegiatatan belajar mengajar baik dijenjang sekolah maupun universitas harus melaksanakan pembelajaran jarak jauh dengan menggunakan e-learning. Pembelajaran e-learning memiliki banyak jenis dan model yang semuanya bagus selama kita dapat menerapkan prinsip pembelajaran e-learning dengan baik dan berkualitas (Giatman et al., 2020).

Proses pembelajaran e-learning ini memiliki beberapa platform yang digunakan untuk menunjang pembelajaran tersebut seperti whatsapp, zoom, google meet dan lain sebagainya. Namun berbeda halnya dengan pembelajaran pendidikan jasmani yang secara umum terdapat materi praktik sehingga terdapat beberapa kendala antara lain sarana dan prasarana, pembelajaran yang tidak terkontrol, pembelajaran praktik yang tidak berjalan dengan baik, dan lain sebagainya. Selain permasalahan tersebut, terdapat permasalahan di lapangan ketika banyak siswa yang mengeluh terhadap tugas yang diterima, siswa melakukan kecurangan saat mengerjakan tugas maupun ujian, permasalahan jaringan, serta kekurangan kemampuan dalam menguasai digital dapat menambah beban kerja (Aristovnik et al., 2020). Berdasarkan hasil penelitian di kota Bengkulu, pembelajaran pendidikan jasmani di era pandemi covid-19 berada pada kategori rendah (Raibowo \& Nopiyanto, 2020). Salah satu kesulitan dalam mengoperasikan kelas, Pendidikan jasmani secara e-learning di sekolah adalah karena kondisi lingkungan yang terbatas dan muatan pendidikan yang akhirnya menurunkan keefektifan dalam pembelajaran (Jeong \& So, 2020).

Pandemi ini memberi dampak pada sistem pendidikan yaitu digitalisasi dan transisi menjadi e-learning yang hasilnya sangat singkat (Coman et al, 2020). Meskipun e-learning adalah solusi supaya pendidikan tetap berjalan, bagaimanapun juga siswa mengalami penurunan belajar saat lockdown dibandingkan ketika tatap muka. Siswa yang berada di rumah merasa stress, cemas dan hal ini berdampak pada kesulitan siswa dalam berkonsentrasi saat mengerjakan tugas sekolah. Selain itu, berkurangnya kontak fisik menyebabkan siswa kekurangan motivasi eksternal serta kemampuan sosio-emosional lainnya (Di Pietro et al, 2020). Beberapa orang tua di Cina mengemukakan bahwa pembelajaran tatap muka lebih baik dalam menciptakan atmosfir belajar dibandingkan $e$ learning (Dong et al, 2020). Beberapa siswa mengatakan bahwa pada awalnya mereka tidak mengalami kesulitan untuk belajar dari rumah, namun semakin lama mereka merasa semakin sukar karena membutuhkan kedisiplinan yang lebih tinggi (Niemi \& Kousa, 2020). Guru memegang peranan penting dalam membantu siswa untuk beradaptasi, tetapi siswa juga perlu bertanggung jawab terhadap pembelajaran mereka seperti manajemen waktu (Gelles et al, 2020). Kreativitas juga perlu dipertahankan dan diasah oleh siswa untuk meningkatkan kemampuan kognitif dan berpikirnya (Narayanan, 2017).

Hal terberat yang dirasakan oleh siswa saat belajar dari rumah adalah motivasi. Sebagian besar siswa mengalami penurunan motivasi. Hal ini disebabkan karena siswa sukar membedakan rumah dengan sekolah, sehingga banyak distraksi saat belajar, contohnya mengerjakan pekerjaan rumah (Yates et al, 2020). Interaksi antar teman di lingkungan sekolah dapat memotivasi individu untuk bekerja keras dan mempelajari kemampuan sosial yang tentu saja tidak bisa diperoleh secara online (Chaturvedi et al, 2021), padahal hasil penelitian sebelum terjadinya pandemi ini membuktikan bahwa e-learning merupakan saran belajar yang fleksibel baik dengan adanya pengajar maupun belajar mandiri, e-learning juga mempermudah siswa untuk belajar secara efektif, namun para pendidik tetap memegang peranan penting dalam pembelajaran termasuk dengan cara e-learning (Luaran et al, 2014). Masalah lain yang muncul ketika e-learning adalah ketidakjujuran siswa dan akademik. Faktor 
penyebabnya adalah kepribadian, kognisi, pengajaran, sistem, dan lainnya (Chen et al, 2020).

Berdasarkan pembahasan yang diungkapkan mengenai aksiologi yang berhubungan dengan nilai pembelajaran serta adanya hambatan pembelajaran saat era pandemi ini, penulis bermaksud untuk mengetahui apakah pembelajaran di era pandemi melalui e-learning ini memiliki hubungan aksiologi yang positif ataukah negatif dalam pembelajaran pendidikan jasmani, khususnya pada nilai tanggung jawab, kedisiplinan, kejujuran, kemandirian, kreativitas, serta sosial siswa. Penelitian ini dirasa penting karna sejauh ini masih sedikitnya hasil penelitian yang mengungkapkan mengenai nilai aksiologi saat pembelajaran e-learning saat pendemi.

\section{METODE PENELITIAN \\ Jenis Penelitian}

Penelitian ini menggunakan jenis deskriptif kuantitatif dengan pendekatan penelitian korelasional untuk mengetahui bagaimana hubungan antara satu variabel dan variabel lainnya. Penelitian ini dilakukan dari 26 Desember 2020 sampai 4 Januari 2021.

\section{Sampel Penelitian}

Populasi penelitian ini adalah SMP Negeri se-Yogyakarta sedangkan sampel yang digunakan adalah 120 orang siswa yang berasal dari tiga sekolah yang berada di Yogyakarta yaitu SMP Negeri 2 Gamping, SMP Negeri 2 Sleman, dan SMP Negeri 9 Yogyakarta. Teknik pengambilan sampel dipilih secara acak dengan teknik random sampling, dan sampel lebih dari seratus orang maka peneliti mengambil 15-25\% (Arikunto, 2009).

\section{Instrumen Penelitian}

Dalam penelitian ini akan membahas hubungan aksiologi dalam pembelajaran pendidikan jasmani pada era pandemi Covid-19, pengukuran dilakukan dengan kuesioner menggunakan skala likert dengan empat penilaian yaitu, sangat setuju, setuju, tidak setuju, dan sangat tidak setuju. Nilai validitas dan realibilitas dari kuesioner dengan nilai 0,887.

\section{Teknik Analisis Data}

Teknik analisis data yang digunakan dalam penelitian ini menggunakan uji regresi linear dan uji korelasi dengan menggunakan SPSS 25.

\section{HASIL}

\section{Hasil Analisis Deskriftif}

Hasil deskriptif dari data penelitian aksiologi hasil belajar pendidikan jasmani melalui $e$ learning di era pandemi Covid-19 yang diperoleh dari tiga SMP yang berada di Yogyakarta yaitu SMP Negeri 2 Gamping, SMP Negeri 2 Sleman, dan SMP Negeri 9 Yogyakarta disajikan pada tabel 1 sebagai berikut. Hasil penelitian pada setiap nilai yang diukur dapat dilihat pada penjelasan masing-masing sub bagian penjelasan dibawah ini:

Tabel 1. Hasil Uji Regresi Linear Aksiologi Hasil belajar Melalui E-Learning.

\begin{tabular}{|c|c|c|c|c|c|}
\hline \multirow[t]{2}{*}{ Model } & \multicolumn{2}{|c|}{$\begin{array}{c}\text { Konstanta } \\
\text { Regresi }\end{array}$} & \multirow{2}{*}{$\begin{array}{c}\begin{array}{c}\text { Standar } \\
\text { Koefisien }\end{array} \\
\text { Beta } \\
\end{array}$} & \multirow[t]{2}{*}{$\mathrm{T}$} & \multirow[t]{2}{*}{ Sig. } \\
\hline & B & Std. Error & & & \\
\hline (Konstanta) & 80.006 & 3.543 & & 22.580 & .000 \\
\hline Tanggung Jawab & .309 & .242 & .188 & 1.279 & .204 \\
\hline Disiplin & -.122 & .195 & -.078 & -.624 & .534 \\
\hline Kemandirian & -.089 & .228 & -.050 & -.389 & .698 \\
\hline Kejujuran & .155 & .183 & .096 & .849 & .397 \\
\hline Kreatifitas & -.041 & .176 & -.025 & -.230 & .818 \\
\hline Sosial & -.024 & .238 & -.011 & -.099 & .921 \\
\hline
\end{tabular}


Dari paparan hasil pada tabel 1, diketahui nilai signifikansi pada setiap indikator aksiologi diperoleh nilai untuk indikator tanggung jawab sebesar 0.204, disiplin 0.534, kemandirian 0.698 , kejujuran 0.397 , kreativitas 0.818 dan sosial 0.921 . Nilai-nilai tersebut lebih dari 0.05 sehingga dapat diambil kesimpulan bahwa indikator-indikator aksiologi dalam pembelajaran pendidikan jasmani melalui e-learning tidak dapat memprediksikan variabel nilai. Kemudian untuk memperjelas hasil uji korelasi aksiologi dalam pembelajaran pendidikan jasmani dapat dilihat pada tabel 2 sebagai berikut:

Tabel 2. Hasil Uji Korelasi Aksiologi Hasil belajar Pendidikan Jasmani Melalui E-Learning.

\begin{tabular}{cccc}
\hline & & Hasil Belajar & Aksiologi \\
\hline Hasil Belajar & Pearson Correlation & 1 & .103 \\
& Sig. (2-tailed) & & .264 \\
Aksiologi & N & 120 & 120 \\
& Pearson Correlation & .103 & 1 \\
& Sig. (2-tailed) & .264 & 120 \\
\hline
\end{tabular}

Dari paparan hasil pada tabel 2, diketahui hasil uji korelasi aksiologi dalam pembelajaran pendidikan jasmani diperoleh nilai signifikan 0,264 . Nilai tersebut lebih besar dari 0,05 sehingga dapat diambil kesimpulan bahwa tidak ada hubungan yang signifikan aksiologi hasil belajar pendidikan jasmani melalui e-learning di era pandemi covid-19.

\section{Indikator Tanggung Jawab}

Hasil penelitian tentang aksiologi pada indikator tanggung jawab tidak dapat memprediksikan variabel nilai. Dari pengategorian berdasarkan angket yaitu $17.5 \%$ masuk ke dalam kategori tinggi, 65.8\% masuk ke dalam kategori sedang dan 16.7\% masuk ke dalam kategori rendah. Untuk memperjelas tampilan hasil penelitian mengenai aksiologi pada nilai tanggung jawab dapat dilihat pada gambar diagram lingkaran 1 di bawah ini:

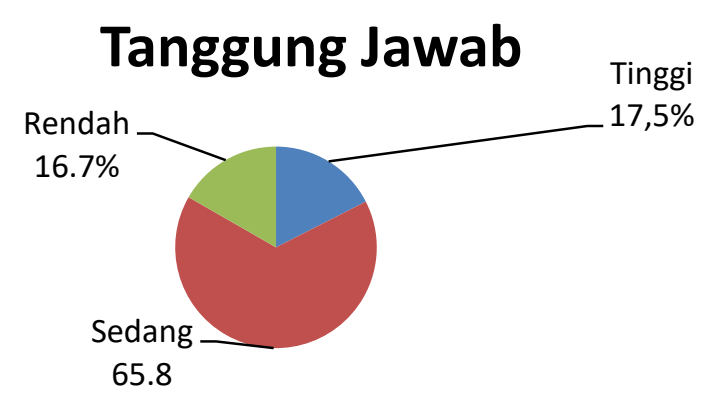

Gambar 1. Hasil Analisis Aksiologi Indikator Tanggung Jawab

\section{Indikator Kedisiplinan}

Hasil penelitian tentang aksiologi pada indikator kedisiplinan tidak dapat memprediksikan variabel nilai. Dari pengategorian berdasarkan angket yaitu15\% masuk ke dalam kategori tinggi, 75\% masuk ke dalam kategori sedang dan 10\% masuk ke dalam kategori rendah. Untuk memperjelas hasil penelitian mengenai aksiologi pada nilai disiplin disajikan pada gambar diagram lingkaran 2 di bawah ini. Indikator disiplin dapat dilihat dalam bentuk diagram sebagai berikut: 
Aulia Gusdernawati ${ }^{*}$, Povian Yona Mahatmasari², Wawan S Suherman ${ }^{3}$, Ahmad Nasrulloh ${ }^{4}$, Kamilia Lituhayu ${ }^{5}$, Aji Khotibul Umam 6

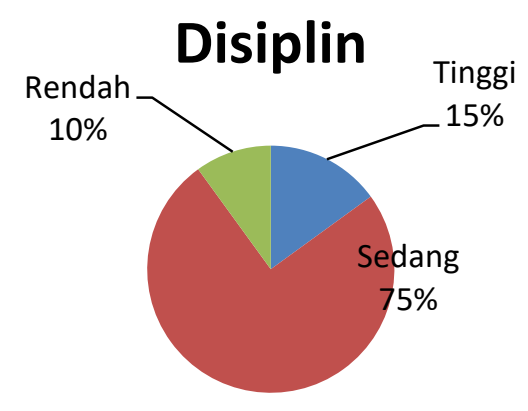

\section{Indikator Kemandirian}

\section{Gambar 2. Hasil Analisis Aksiologi Indikator Disiplin}

Hasil penelitian tentang aksiologi pada indikator kemandirian tidak dapat memprediksikan variabel nilai. Dari pengategorian berdasarkan angket yaitu $16.7 \%$ masuk ke dalam kategori tinggi, 62.5\% masuk ke dalam kategori sedang dan $20.8 \%$ masuk ke dalam kategori rendah. Untuk memperjelas hasil penelitian mengenai aksiologi pada nilai disiplin disajikan pada gambar diagram lingkaran 3 di bawah ini. Indikator disiplin dapat dilihat dalam bentuk diagram sebagai berikut:

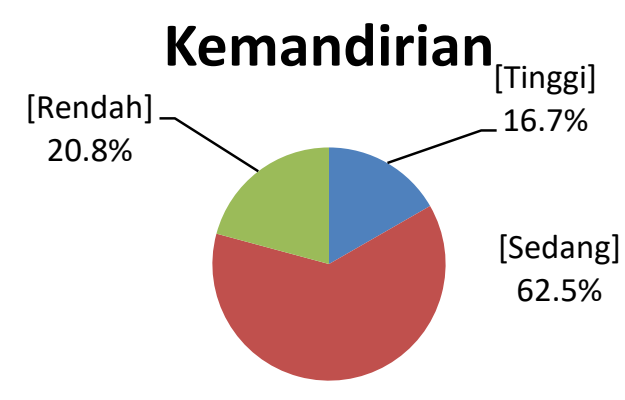

Gambar 3. Hasil Analisis Aksiologi Indikator Kemandirian

\section{Indikator Kejujuran}

Hasil penelitian tentang aksiologi pada indikator kejujuran tidak dapat memprediksikan variabel nilai. Dari pengategorian berdasarkan angket yaitu 24.2\% masuk ke dalam kategori tinggi, 65.8\% masuk ke dalam kategori sedang dan 10\% masuk ke dalam kategori rendah. Untuk memperjelas hasil penelitian mengenai aksiologi pada nilai disiplin disajikan pada gambar diagram lingkaran 4 di bawah ini. Indikator disiplin dapat dilihat dalam bentuk diagram sebagai berikut:

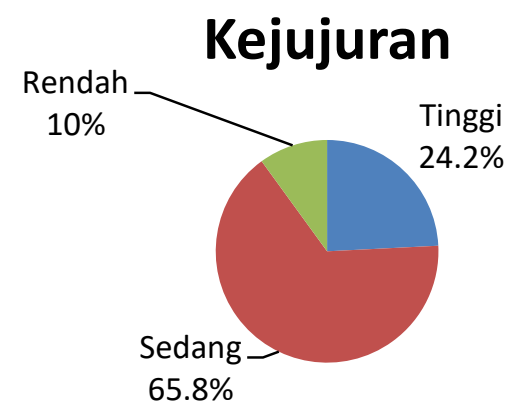

Gambar 4. Hasil Analisis Aksiologi Indikator Kejujuran 
Aulia Gusdernawati ${ }^{*}$, Povian Yona Mahatmasari², Wawan S Suherman ${ }^{3}$, Ahmad Nasrulloh ${ }^{4}$, Kamilia Lituhayu ${ }^{5}$, Aji Khotibul Umam 6

\section{Indikator Kreativitas}

Hasil penelitian tentang aksiologi pada indikator kreativitas tidak dapat memprediksikan variabel nilai. Dari pengategorian berdasarkan angket yaitu $12.5 \%$ masuk ke dalam kategori tinggi, 74.2\% masuk ke dalam kategori sedang dan 13.3\% masuk ke dalam kategori rendah. Untuk memperjelas hasil penelitian mengenai aksiologi pada nilai disiplin disajikan pada gambar diagram lingkaran 5 di bawah ini. Indikator disiplin dapat dilihat dalam bentuk diagram sebagai berikut:

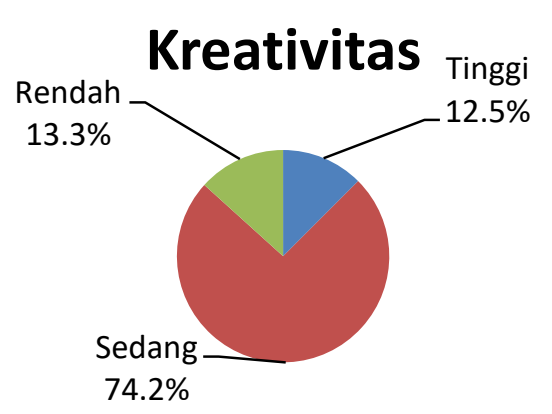

Gambar 5. Hasil Analisis Aksiologi Indikator Kreativitas

\section{Indikator Sosial}

Hasil penelitian tentang aksiologi pada indikator sosial tidak dapat memprediksikan variabel nilai. Dari pengategorian berdasarkan angket yaitu 22.5\% masuk ke dalam kategori tinggi, 54.2\% masuk ke dalam kategori sedang dan 23.3\% masuk ke dalam kategori rendah. Untuk memperjelas hasil penelitian mengenai aksiologi pada nilai disiplin disajikan pada gambar berikut:

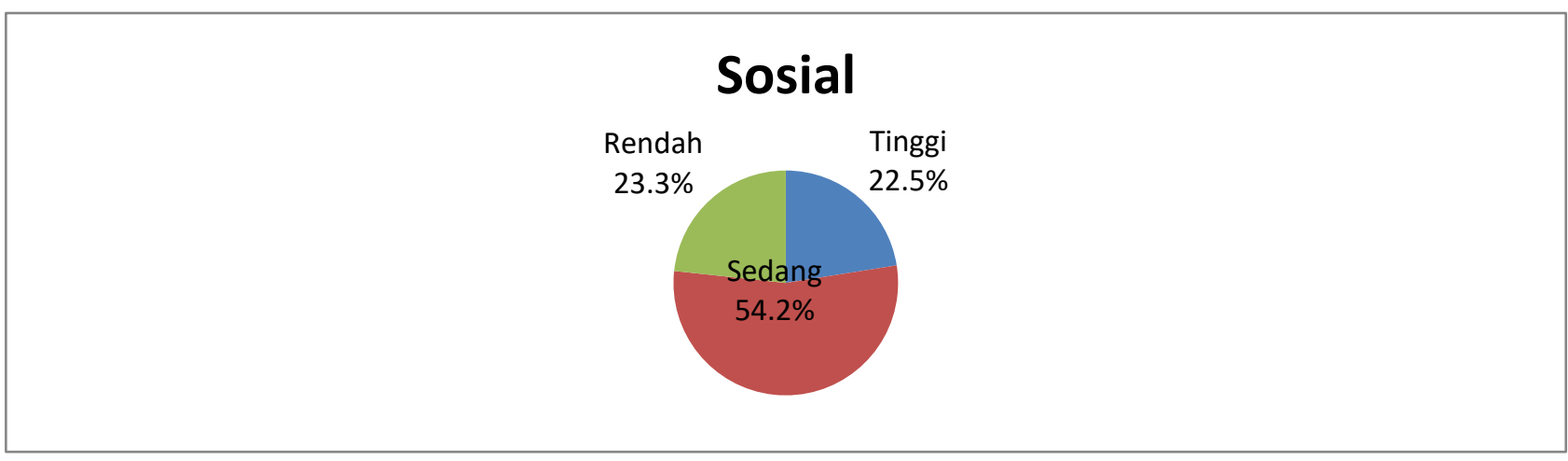

Gambar 6. Hasil Analisis Aksiologi Indikator Sosial

\section{PEMBAHASAN}

Berdasarkan hasil analisis penelitian yang dilakukan, menyebutkan bahwa tidak ada hubungan antara nilai aksiologi pada pendidikan jasmani secara online pada era pandemi covid-19 dengan nilai signifikan yang didapatkan 0,264. Data dalam penelitian ini pada nilai tanggung jawab masih terdapat siswa yang berada dalam kategori rendah sebesar 16,7\%. Hal ini disebabkan adanya siswa yang tidak memiliki kesiapan diri untuk mengikuti pembelajaran e-learning. Model pembelajaran e-learning ini diberlakukan dengan transisi waktu yang singkat dan di dalam pembelajaran e-learning tersebut guru mengalami kesulitan untuk mengontrol seluruh siswa. Oleh karena itu, proses pembelajaran harus didukung dengan nilai kedisiplinan.

Hasil penelitian yang didapatkan jika dikaitkan dengan penelitian terdahulu memiliki 
Aulia Gusdernawati ${ }^{*}$, Povian Yona Mahatmasari², Wawan S Suherman³ ${ }^{3}$ Ahmad Nasrulloh ${ }^{4}$, Kamilia Lituhayu ${ }^{5}$, Aji Khotibul Umam ${ }^{6}$

persamaan, penelitian tanggung jawab. Hidayat, Rohaya, Nadine, \& Ramadhan,(2020) menjelaskan jika pembelajaran online yang dilakukan memiliki beberapa dampak kurang baik pada beberapa karakter siswa. Lebih lanjut, diungkapkan jika rendahnya kemandirian serta tanggung jawab belajar siswa. Selain itu dijelaskan jika menghadapi pembelajaran online, siswa belum siap serta belum dapat memaksimalkan dibanding dengan pembelajaran yang dilakukan secara langsung. Efektif tidaknya pembelajaran online bergantung pada teknologi, jaringan internet serta karakter yang dimiliki oleh mahasiswa serta dosen akan mempengaruhi bagaimana tanggung jawab terhadap pembelajaran (Fauziyah, 2020).

Pada nilai kedisiplinan masih ada siswa yang memiliki kedisiplinan yang rendah. Hal ini dibuktikan dengan data dalam kategori rendah sebesar 10\%, yang disebabkan oleh kelonggaran dari pembelajaran pendidikan jasmani seperti pengumpulan tugas video atau tugas tertulis menggunakan aplikasi Google Classroom yang ditentukan batas waktunya, tetapi saat penyerahan tugas tidak mengumpulkan tugasnya sesuai dengan waktu yang telah ditentukan.

Hasil yang didapatkan jika dikaitkan dengan penelitian terdahulu memiliki perbedaan. Disiplin saat pembelajaran online. Apriyanti, (2020) mengungkapkan jika siswa tertib dalam melaksanakan program e-learning yang diberikan oleh guru, disebabkan guru sudah menetapkan ataupun melakukan mapping sebelum memulai pembelajaran. Sehingga siswa sudah mengetahui hal-hal yang harus dipenuhi dalam pembelajaran online Hal ini menjelaskan jika pembelajaran dari yang diberikan kepada siswa saat pandemi memiliki nilai tinggi, dalam artian siswa disiplin dalam mengikuti pembelajaran online yang diberikan oleh guru (Anas \& Fitriani, 2019).

Disiplin pembelajaran online yang dilakukan dapat terlaksana dengan baik apabila adanya kerja sama antara guru serta siswa (Kusumadewi et al., 2020). Pada nilai kemandirian siswa yang masuk dalam kategori rendah sebesar 16,7\%. Hal ini dipengaruhi oleh model pembelajaran jarak jauh yang tidak efektif. Ada dua hal yang menyebabkan terjadinya model pembelajaran tidak efektif. Pertama, pengerjaan tugas tidak terpantau langsung oleh guru. Kedua, beban tugas yang diberikan guru kepada siswa terlalu banyak, sehingga pembagian waktu tidak maksimal dan justru tugas lebih banyak mendapat bantuan dari orang lain.

Hasil yang didapatkan memiliki persamaan dengan hasil penelitian ataupun teori terdahulu, Kemandirian siswa saat pembelajaran online mengalami penurunan. Hal ini disebabkan belum mampu dalam mempersiapkan pembelajaran secara benar Hidayat et al., (2020). Kusumadewi, Yustiana, \& Nasihah, (2020).menjelaskan jika rendahnya kemandirian siswa saat melakukan pembelajaran online. Rendahnya tingkat kemandirian siswa dalam pembelajaran online perlu ditingkatkan dengan cara penanaman pembelajaran karakter kepada siswa agar mampu melakukan pembelajaran secara mandiri. Tidak adanya perbedaan yang mendalam antara kemandirian siswa dalam mengikuti pembelajaran online ataupun tidak, tetapi siswa memerlukan pembiasan pembelajaran (Ambiyar et al., 2020).

Pada nilai kejujuran di kategori rendah sebesar 10\%. Nilai kejujuran di dalam pembelajaran e-learning sangat kompleks untuk dibahas terutama pada pelaksanaan ujian. Berbagai macam peraturan telah ditetapkan sekolah agar pelaksanaan ujian terlaksana dengan maksimal tanpa adanya indikasi kecurangan dalam pengisian jawaban. Tetapi, keadaan yang ditemukan di lapangan berbeda. Siswa memiliki banyak cara dalam menjawab soal ujian dan mengambil kesempatan untuk mendapatkan nilai yang baik sehingga pembelajaran e-learning telah menimbulkan problematika dalam pengembangan kreatifitas siswa. Kajian literatur terdahulu mengungkapkan hal yang sama.

Penelitian (McGee, 2013) mengungkapkan jika perlunya kejujuran saat kelas online perlu diperhatikan karena terjadinya pergeseran sistem pembelajaran. Hal yang sering terjadi saat pembelajaran online adalah siswa menyontek dan menjiplak saat pengerjaan tugas. 
Aulia Gusdernawati ${ }^{*}$, Povian Yona Mahatmasari², Wawan S Suherman³ ${ }^{3}$ Ahmad Nasrulloh ${ }^{4}$, Kamilia Lituhayu ${ }^{5}$, Aji Khotibul Umam ${ }^{6}$

Masalah yang dihadapi saat pembelajaran online masa pandemi adalah mengenai karakter siswa meliputi ketidakjujuran akademis pada khususnya.

Tantangan utama yang diidentifikasi dalam penilaian jarak jauh adalah ketidakjujuran akademik, infrastruktur, cakupan hasil pembelajaran, dan komitmen siswa untuk mengirimkan penilaian. Untuk meminimalkan ketidakjujuran akademik, menyiapkan pertanyaan yang berbeda untuk setiap siswa merupakan pendekatan terbaik (Guangul et al., 2020). Pada hasil analisis nilai kreativitas berada dalam kategori sedang sebesar 74,2\%. Siswa mengalami keterbatasan dalam pembelajaran e-learning yang meliputi sarana prasana dalam pembelajaran pendidikan jasmani sehingga menghambat kreativitas peserta didik. Kebijakan pembelajaran dari rumah yang membatasi interaksi fisik menyebabkan tidak adanya interaksi sosial, sehingga komunikasi verbal dan nonverbal tidak digunakan dengan benar (Rochman et al., 2020).

Hal ini terbukti dengan masih adanya siswa yang memiliki nilai sosial sebesar $23.3 \%$. Adanya pembatasan sosial pada era pandemi covid-19 ini membuat komunikasi antar siswa dan guru menjadi terbatas. Pada hasil penelitian terdapat perbedaan dengan kajian literatur terdahulu yang mengungkapkan jika pada masa pembelajaran online karena covid-19 siswa lebih aktif dalam mengikuti pembelajaran. Pendidikan yang dilakukan secara online dapat lebih meningkatkan produktivitas siswa secara kreatif. Selanjutnya, diungkapkan jika siswa mampu meningkatkan serta berpikir secara kritis serta mengembangkan kemampuan dalam pembelajaran online (Rochman et al., 2020).

Berdasarkan dari hasil penelitian yang didapatkan pada tiga SMP yang berada di Yogyakarta, nilai aksiologinya tidak dapat memprediksi pembelajaran pendidikan jasmani melalui $e$ - learning. Hal ini disebabkan keterbatasan pembelajaran e-learning yang sangat kompleks, baik siswa maupun guru. Beberapa nilai yang perlu untuk diedukasi kepada siswa pada saat pembelajaran e-learning, misalnya tentang nilai kejujuran dan tanggung jawab. Kedua nilai ini masih sangat perlu ditingkatkan pada hasil belajar e-learning. Baik nilai kejujuran maupun nilai sosial merupakan nilai yang menjadi dasar dalam saling menghargai, sopan santun, dan komunikasi yang lebih baik. Penerapan aksiologi pada dunia pendidikan ialah menguji dan menggabungkan nilai tersebut dalam kehidupan manusia dan membentuknya dalam kepribadian siswa (Sulistyawati, 2020). Keterbatasan jangkauan wilayah menjadi kekurangan dalam penelitian. Selain itu, kejujuran sampel pada pengisian kuesioner juga menjadi kendala pada penelitian ini. Harapannya, akan ada penelitian yang cakupannya lebih luas dari penelitian ini.

\section{SIMPULAN}

Hasil penelitian yang diungkapkan dapat ditarik kesimpulan yaitu, tidak adanya hubungan aksiologi pada hasil pembelajaran penjasorkes melalui e-learning. Diungkapkan jika pada pembelajaran e-learning ini diharapkan peserta didik tetap konsisten berpadu dengan keseluruhan nilai-nilai aksiologi sehingga pembelajaran yang dilakukan akan mendapatkan hasil yang maksimal. Pentingnya menerapapkan nilai aksiologi saat pembelajaran dikarenakan melalui pembelajran serta Pendidikan mampu menjadi pembentuk kepribadian untuk memperluas pengetahuan dan keterampilan yang akan mempengaruhi kehidupan. Selain itu, pentingnya peran keluarga untuk memperhatikan pembelajaran saat $e$ leaning sehingga siswa mampu mengikuti pembelajaran dengan baik dan mampu mendapaykan prestasi maksimal pada pembelajaran khususnya pembelajaran penjas.

\section{DAFTAR PUSTAKA}

Aleksandrovich, V. S. (2013). Axiology of modern Russian education system. ANALITIKA RODIS, 52-57. 
Aulia Gusdernawati ${ }^{*}$, Povian Yona Mahatmasari², Wawan S Suherman ${ }^{3}$, Ahmad Nasrulloh ${ }^{4}$, Kamilia Lituhayu ${ }^{5}$, Aji Khotibul Umam 6

Ambiyar, Aziz, I., \& Melisa. (2020). Perbedaan Kemandirian Belajar Siswa pada Masa Pandemi di SMAN 1 Lembah Melintang dan SMAN 1 Lembah Gumanti. Cendekia, 04(02), 12461258.

Anas, A., \& Fitriani, A. (2019). Dampak Media E-Learning Terhadap Kedisiplinan Dalam Mengerjakan Tugas Dan Motivasi. Pedagogy: P-ISSN: 2502-3802 e-ISSN: 2502-3799, 4(1), 74-82.

Apriyanti, N. (2020). Analisis Evaluasi Pembelajaran Daring Berorientasi. Jurnal Pendidikan Dasar.

Aristovnik, A., Keržič, D., Ravšelj, D., Tomaževič, N., \& Umek, L. (2020). Impacts of the COVID19 pandemic on life of higher education students: A global perspective. Sustainability (Switzerland), 12(20), 1-34. https://doi.org/10.3390/su12208438

Chaturvedi, K., Vishwakarma, D. K., \& Singh, N. (2021). COVID-19 and its impact on education, social life and mental health of students: A survey. Children and Youth Services Review, 121(July 2020), 105866. https://doi.org/10.1016/j.childyouth.2020.105866

Chen, C., Long, J., Liu, J., Wang, Z., Wang, L., \& Zhang, J. (2020). Online Academic Dishonesty of College Students: A Review. 448, 156-161. https://doi.org/10.2991/assehr.k.200723.121

Coman, C., Țîru, L. G., Meseșan-Schmitz, L., Stanciu, C., \& Bularca, M. C. (2020). Online teaching and learning in higher education during the coronavirus pandemic: Students' $\begin{array}{llll}\text { perspective. } & \text { Sustainability } & \text { (Switzerland), } & 12(24),\end{array}$ https://doi.org/10.3390/su122410367

Di Pietro, G., Biagi, F., Costa, P., Karpiński, Z., \& Mazza, J. (2020). The Likely Impact of COVID19 on Education: Reflections based on the Existing Literature and Recent International Datasets. In Publications Office of the European Union, Luxembourg: Vol. EUR 30275 (Issue JRC121071). https://doi.org/10.2760/126686

Dong, C., Cao, S., \& Li, H. (2020). Young Children's Online Learning During COVID-19 Pandemic: Chinese Paren's Beliefs and Attitudes. Children and Youth Srevices Review, 118(January), 1-9.

Dwi, B., Amelia, A., Hasanah, U., \& Putra, A. M. (2020). Analisis Keefektifan Pembelajaran Online di Masa Pandemi Covid-19. Jurnal Pendidikan Guru Sekolah Dasar, 2(1), 3.

Fauziyah, N. (2020). Dampak Covid-19 Terhadap Efektivitas Pembelajaran Daring Pendidikan Islam. Al-Mau'Izhoh, 2(2), 1-11.

Gelles, L. A., Lord, S. M., Hoople, G. D., Chen, D. A., \& Mejia, J. A. (2020). Compassionate flexibility and self-discipline: Student adaptation to emergency remote teaching in an integrated engineering energy course during covid-19. Education Sciences, 10(11), 1-23. https://doi.org/10.3390/educsci10110304

Giatman, M., Siswati, S., \& Basri, I. Y. (2020). Online Learning Quality Control in the Pandemic 
Aulia Gusdernawati ${ }^{*}$, Povian Yona Mahatmasari², Wawan S Suherman ${ }^{3}$, Ahmad Nasrulloh ${ }^{4}$, Kamilia Lituhayu ${ }^{5}$, Aji Khotibul Umam 6

Covid-19 Era in Indonesia. Journal of Nonformal Education, 6(2), 168-175. https://journal.unnes.ac.id/nju/index.php/jne

Guangul, F. M., Suhail, A. H., Khalit, M. I., \& Khidhir, B. A. (2020). Challenges of remote assessment in higher education in the context of COVID-19: a case study of Middle East College. Educational Assessment, Evaluation and Accountability, 32(4), 519-535. https://doi.org/10.1007/s11092-020-09340-w

Haerudin, Cahyani, A., Sitihanifah, N., Setiani, R. N., Nurhayati, S., Oktaviana, V., \& Sitorus, Y. I. (2020). Peran Orangtua Dalam Membimbing Anak Selama Pembelajaran Di Rumah Sebagai Upaya Memutus Covid-19. Universitas Singaperbangsa Karawang, 1-12.

Hidayat, D. R., Rohaya, A., Nadine, F., \& Ramadhan, H. (2020). Kemandirian Belajar Peserta Didik Dalam Pembelajaran Daring Pada Masa Pandemi Covid -19. Perspektif Ilmu Pendidikan, 34(2), 147-154. https://doi.org/10.21009/pip.342.9

Jeong, H. C., \& So, W. Y. (2020). Difficulties of online physical education classes in middle and high school and an efficient operation plan to address them. International Journal of Environmental Research and Public Health, 17(19), 1-13. https://doi.org/10.3390/ijerph17197279

Kemendikud. (2020). Surat Edaran Nomor 15 Tahun 2020 Tentang Pedoman Penyelenggaraan Belajar Dari Rumah Dalam Masa Darurat Penyebarana Corona Virus Disease (Covid-19).

Kusumadewi, R. F., Yustiana, S., \& Nasihah, K. (2020). Menumbuhkan Kemandirian Siswa Selama Pembelajaran Daring Sebagai Dampak COVID-19 Di SD. JRPD (Jurnal Riset Pendidikan Dasar), 1(1), 7-13.

Luaran, J. @ E., Samsuri, N. N., Nadzri, F. A., \& Rom, K. B. M. (2014). A Study on the Student's Perspective on the Effectiveness of Using e-learning. Procedia - Social and Behavioral Sciences, 123, 139-144. https://doi.org/10.1016/j.sbspro.2014.01.1407

McGee, P. (2013). Supporting academic honesty in online courses. Journal of Educators Online, 10(1). https://doi.org/10.9743/JE0.2013.1.6

Narayanan, S. (2017). A Study on the Relationship between Creativity and Innovation in Teaching and Learning Methods towards Students Academic Performance at Private Higher. International Journal of Academic Research in Bussiness and Social Science, 7, 110. https://doi.org/10.6007/IJARBSS/v7-i14/3647

Niemi, H. M., \& Kousa, P. (2020). A Case Study of Students' and Teachers' Perceptions in a Finnish High School during the COVID Pandemic. International Journal of Technology in Education and Science, 4(4), 352-369. https://doi.org/10.46328/ijtes.v4i4.167

Putri, N. A. (2013). Penanaman Nilai-Nilai Pendidikan Karakter Melalui Mata Pelajaran Sosiologi. KOMUNITAS: International Journal of Indonesian Society and Culture, 3(2), 205-215. https://doi.org/10.15294/komunitas.v3i2.2317

Raibowo, S., \& Nopiyanto, Y. E. (2020). Proses Belajar Mengajar PJOK di Masa Pandemi Covid- 
Aulia Gusdernawati ${ }^{*}$, Povian Yona Mahatmasari², Wawan S Suherman ${ }^{3}$, Ahmad Nasrulloh ${ }^{4}$, Kamilia Lituhayu ${ }^{5}$, Aji Khotibul Umam 6

19. 1, 49-55.

Rochman, C., Nasrudin, D., Rokayah, R., Mulyani, S., Pertiwi, C. S. R., \& Ginanjar, G. (2020). Distance Learning During the Covid-19 Pandemic: Strengthening of Character, Productivity, and Stem Competency. Jurnal Pena Sains, 7(2), 130-140. https://doi.org/10.21107/jps.v7i2.8261

Siregar, L. Y. S. (2017). Full day school sebagai penguatan pendidikan karakter (Perspektif psikologi pendidikan islam). Fikrotuna, 5(1).

Sirojudin, D., \& Ashoumi, H. (2020). Aksiologi Ilmu Pengetahuan Manajemen Pendidikan Islam. Al-Idaroh: Jurnal Studi Manajemen Pendidikan Islam, 4(2), 182-195.

Soeprapto, S. (2013). An Axiological foundation of the indonesian national education system in the perspective of philosophy of education. Cakrawala Pendidikan, 2, 266-276.

Suriasumantri, J. S. (2015). Filsafat Ilmu: Sebuah Apresiasi Terhadap Ilmu, Agama dan Seni. Pustaka Sinar Harapan.

Tomar, B. (2014). Axiology in teacher education: Implementation and challenges. IOSR Journal of Research \& Method in Education, 4(2), 51-54.

Wahono, M. (2018). Pendidikan karakter: Suatu kebutuhan bagi mahasiswa di era milenial. Integralistik, 29(2), 1-7. https://doi.org/10.15294/integralistik.v29i2.16696

Winata, K. A., Sahudi, \& Hasanah, A. (2020). Landasan teori pendidikan karakter disekolah (tinjauan ontologi, epistimologi dan aksiologi. Jurnal Al Amar, 1(3), 50-56.

Yates, A., Starkey, L., Egerton, B., Flueggen, F., Yates, A.. (2020). High school students ' experience of online learning during covid-19: The influence of technology and pedagogy 19: the influence of technology and pedagogy. Technology, Pedagogy and Education, 1-15. https://doi.org/10.1080/1475939X.2020.1854337 